\title{
EVALUASI SISTEM MANAJEMEN SUMBER DAYA MANUSIA PADA PENEMPATAN KERJA PETUGAS DI UPT PUSKESMAS MALINGPING
}

\author{
Mita Melisa Febriani' ${ }^{1}$, Syamsul Hidayat ${ }^{2}$, Saepudin $^{3}$ \\ 1,2,3 Universitas Bina Bangsa \\ mitamelisa25@gmail.com
}

\begin{abstract}
Abstrak
Salah satu sumber daya yang penting dalm manajemen adalah sumber daya manusia atau human resources. Pentingnya sumber daya manusia ini, perlu disadari oleh semua tingkatan manajemen. Bagaimanapun majunya teknologi saat ini, namun faktor manusia tetap memegang peranan penting bagi keberhasilan suatu Puskesmas. Penelitian ini bertujuan untuk mengevaluasi sistem manajemen sumber daya manusia pada perencanaan, pengorganisasian, pengarahan, dan pengendalian terhadap penempatan kerja petugas di UPT Puskesmas Malingping. Jenis penelitian yang digunakan dalam penelitian ini adalah penelitian kualitatif fenomenologi yaitu pengamatan, wawancara mendalam dan dokumentasi. Hasil penelitian menunjukkan bahwa Puskesmas Malingping melaporkan kekurangannya ke Dinas Kesehatan dengan melihat kekosongan tenaga di Puskesmas. Tenaga kesehatan Bidan dan Perawat yang tidak memiliki kompetensi di bidang manajemen, UKP Farmasi dan Analisis Lab terpaksa harus mengisi kekosongan bagian tersebut dikarenakan kurangnya tenaga kerja. Kesimpulan dari penelitian ini menunjukkan bahwa sistem manajemen sumber daya manusia di Puskesmas Malingping meliputi empat aspek yaitu perencanaan, pengorganisasiaan, pengarahan dan pengendalian dan evaluasinya menunjukkan bahwa sistem manajemen sumber daya manusia pada penempatan kerja di UPT Puskesmas Malingping belum maksimal dikarenakan kurangnya tenaga kesehatan yang mengakibatkan penempatan kerja yang tidak sesuai dengan disiplin ilmu.

Kata Kunci: Perencanaan, Pengorganisasian, Pengarahan, Pengendalian, Sumber Daya manusia
\end{abstract}

\begin{abstract}
One of the important resources in management is human resources. The importance of human resources needs to be realized by all levels of management. However advanced technology is today, the human factor still plays an important role for the success of a Puskesmas. The study aims to evaluate the HR management system in planning, organizing, directing, and contolling the work placement of officers at Puskesmas Malingping. The type of research used in the research is qualitative fenomenology research, namely observation, in-depth interviews and documentation. The resuls showed that the Puskesmas Malingping reports the shortage to the health office by looking at the vacancies in the health center. Health workers, midwives and nurses who do not have competence in the fields of management, UKP Pharmachy and laboratory analysis are forced to fill the vacancies in these sections due to a lack of manpower. The conclusion of this researcher shows that the human resource management system at the puskesmas Malingping four aspects, namely planning, organizing, directing and controlling and its evaluation shows that the human resource management system in work placements at the puskesmas Malingping has not been maximized due to the lack of health works resulting in placement work that is not in accordance with the disiplince of science.
\end{abstract}


Keywords: Briefing, Control, Human Resources, Organizing Planning

\section{PENDAHULUAN}

Sumber daya manusia merupakan kekuatan daya fikir dan berkarya manusia yang masih tersimpan dalam diri, yang perlu digali, dibina, dikembangkan untuk dimanfaatkan sebaik-baiknya bagi kesejahteraaan kehidupan manusia yang terdiri dari kemampuan, berkomunikasi, bertindak, dan bermoral untuk melaksanakan suatu kegiatan. Manajemen sumber daya manusia merupakan suatu proses pemanfaatan sumber daya manusia secara efektif dan efisien melalui kegiatan perencanaan, pengorganisasian, pengarahan dan pengendalian semua nilai yang menjadi kekuatan manusia untuk mencapai tujuan.

Salah satu indikator dalam mencapai tujuan yang telah ditetapkan tersebut adalah adanya peran aktif dari pegawai atau karyawan sebagai salah satu komponen sistem organisasi. Pegawai mempunyai peran yang utama dalam setiap kegiatan organisasi, karena pegawai menjadi perencana, pelaku, dan penentu terwujudnya tujuan sistem organisasi. Tujuan organisasi akan lebih mudah dicapai apabila pegawai ditempatkan pada posisi yang sesuai dengan kompetensi yang dimilikinya. Tetapi kompetensi dan kemampuan saja tidak cukup untuk meningkatkan kinerja pegawai, dibutuhkan juga ketepatan dalam menempatkan pegawai sesuai dengan kompetensi dan kemampuannya

Penempatan kerja merupakan salah satu faktor penting yang tidak boleh diabaikan dalam mencapai tujuan instansi atau lembaga. Dewasa ini kebanyakan organisasi melakukan pengadaan (recruitment) karyawan melalui system kedekatan (nepotisme) dan juga melalui sistem sogokan (kolusi). Artinya pihak organisasi tidak memperhatikan betul latar belakang dari tingkat pendidikan, pengalama, kesehatan fisik dan mental, dan usia dari pegawai itu sendiri. Jika organisasi menempatakan pegawai pada tempat yang bukan keahliannya maka kinerja karyawan tidak maksimal sehingga tujuan organisasi tidak efektif dan efisien

Menurut Peraturan Menteri kesehatan Republik Indonesia Nomor 75 Tahun 2014 Tentang Pusat Kesehatan Masyarakat. Pusat Kesehatan Masyarakat yang selanjutnya disebut Puskesmas adalah fasilitas pelayanan kesehatan yang menyelenggarakan upaya kesehatan masyarakat dan upaya kesehatan perseorangan tingkat utama, dengan lebih mengutamakan upaya promotif dan preventif, untuk mencapai derajat kesehatan masyarakat yang setinggi-tingginya di wilayah kerjanya. 
Puskesmas adalah fasilitas sarana pelayanan kesehatan terdepan dan merupakan ujung tombak pelayanan kesehatan di seluruh Tanah Air, utamanya dalam era Badan Penyelenggara Jaminan Sosial (BPJS). Keberhasilan pelayanan kesehatan melalui Puskesmas memberikan konstribusi yang cukup besar dalam pembangunan kesehatan. Puskesmas merupakan Unit Pelayanan Teknis Dinas kesehatan kabupaten/kota yang bertanggung jawab menyelenggarakan pembangunan kesehatan di suatu wilayah kerja

Penempatan kerja pegawai pada Puskesmas Malingping ternyata masih terdapat tenaga kerja kesehatan yang ditempatkan dibidang yang tidak sesuai dengan latar belakang pendidikannya. Apabila menilik persyaratan ketenagaan puskesmas rawat inap sesuai dengan standar Permenkes No. 75 Tahun 2014, Puskesmas Rawat Inap Malingping masih kekurangan tenaga kerja kesehatan untuk jenis tenaga analisis laboratorium. Tenaga kesehatan lainnya sudah memadai. Sebagai pelaksananya ditugaskan tenaga kesehatan lain. Misalnya tenaga perawat yang melaksanakan program kesehatan lingkungan serta tenaga fungsional namun yang telah dilatih khusus untuk melaksanakan pelayanan laboratorium.

Tenaga kerja kesehatan yang merupakan Bidan atau Perawat tidak memiliki kompetensi di bidang manajemen. Namun karena kurangnya tenaga kerja pada bagian manajemen, maka tenaga kerja kesehatan bagian Bidan dan Perawat yang terlalu banyak terpaksa harus mengisi kekosongan bagian tersebut. Kesalahan dalam penempatan pegawai yang tidak sesuai dengan kebutuhan akan mengakibatkan timbulnya konflik pada diri pegawai yang berkaitan dengan pekerjaan yang kemudian dapat mengakibatkan menurunnya semangat dan gairah kerja sehingga pada akhirnya mengakibatkan menurunnya produktivitas kerja.

Penelitian ini bertujuan untuk melihat bagaimana sistem manajemen SDM pada penempatan kerja petugas di UPT Puskesmas Malingping.

\section{METODE PENELITIAN}

Penelitian ini menggunakan metode kualitatif dengan kasus fenomenologi deskriptif yaitu penelitian yang bermaksud untuk memahami fenomena tentang apa yang dialami oleh subjek penelitian, secara biostik dan dideskripsikan dalam bentuk kata-kata dan bahasa, pada suatu konteks khusus yang alamiah dan dengan memanfaatkan metode alamiah 
Informan dalam penelitian ini yaitu terdiri dari informan kunci Kepala Puskesmas Malingping, Kepala Tata Usaha, Kepegawaian, Perawat, dan Tenaga Kerja Non-Medis di Puskesmas Malingping.

\section{HASIL DAN PEMBAHASAN}

\section{HASIL}

\section{Deskripsi subjek penelitian}

Jumlah subjek penelitian ini adalah 5 orang yang dianggap dapat memberikan informasi yang lengkap dan akurat. Kelima subjek tersebut ialah kepala puskesmas sebagai pengambil kebijakan, tata usaha dan bagian kepegawaian sebagai pengelolah bagian kepegawaian, perawat dan tenaga kerja non-medis sebagai tim mutu yang menangani bagian mutu pelayanan puskesmas.

Adapun desktipsi subyek penelitian yang berhasil diwawancarai secara sederhana dapat diuraikan pada tabel berikut:

\begin{tabular}{|l|l|l|l|}
\hline No & Nama & Usia & Jabatan \\
\hline 1 & JS & 57 Tahun & Kepala Puskesmas \\
\hline 2 & WNH & 49 Tahun & Kepala kepegawaian \\
\hline 3 & YSA & 46 Tahun & KASUBAG TU \\
\hline 4 & RA & 23 Tahun & Perawat \\
\hline 5 & INH & 23 Tahun & Pegawai Non-Medis \\
\hline
\end{tabular}

Evaluasi sistem manajemen sumber daya manusia pada penempatan kerja

Setelah melakukan observasi dan wawancara pada Kepala Puskesmas Malingping, KASUBAG TU, Kepegawaian, Perawat, dan Pegawai Non-Medis. Maka hasil yang dikelompokkan berdasarkan variable yang diteliti dalam penelitian ini.

Kesimpulan dapat ditarik dari hasil penelitian melalui variable yang diteliti diantaranya :

\section{Perencanaan}

Perencanaan tenaga kesehatan di Puskesmas harus sesuai dengan tingkat kebutuhan Puskesmas dalam membantu terwujudnya tujuan. Tujuan dari informasi tersebut untuk mengetahui bagaimana kejelasan informasi tentang sistem manajemen di UPT Puskesmas Malingping yang telah di ungkapkaninforman berikut. 
Prosiding The 1st National Conference on Applied Business, Education, \& Technology (NCABET)"

Unversitas Bina Bangsa 2021

DOI Article : 10.46306/ncabet.v1i1.4

"kalau untuk sumber daya manusia sebenarnya kita sudah ini yah ehh belum, belum menerapkan kemenkes juga soalnya ada beberapa tenaga yang kita tidak ada. Misalnya apoteker kita belum ada analis laboratorium juga kita belum punya, eh kita sudah mengusulkan melalui aplikasi juga rencana kebutuhan tenaga SDM melalu aplikasi itu yang diinput dan di monitor di Dinas Kesehatan."

Berdasarkan jawaban dari bapak JS tersebut dapat kita ketahui bahwa sistem manajemen SDM di Puskesmas Malingping masih belum sesuai dengan aturan Kemenkes karena masih ada beberapa tenaga kerja yang tidak dimiliki di Puskesmas Malingping.

"Mulai tahun 2020 Puskesmas Malingping dituntut untuk mandiri termasuk dalam manajemen SDM mulai menentukan kebutuhan SDM, organisasi, penilaian dan pengembangan SDM karena berbadan hukum BLUD."

Dari jawaban tersebut diatas dapat diketahui bahwa sistem manajemen SDM di Puskesmas Malingping sudah berbadan hukum BLUD.

\section{Pengorganisasian}

Distruktur organisasi sudah ditetapkan nama-nama yang bertanggung jawab dibagia tertentu dan satu petugas bertanggung jawab denga bidang atau bagiannya masing-masing sesuai dengan aturan. Seperti kutipan hasil wawancara berikut.

"kalau untuk struktur organisasi di Puskesmas ada beberapa yang sudah tadi saya sebutkan belum ada tenaganya ya, seperti laboratorium kemudian apoteker, kita apoteker kan sementara masih apoteker yang basic pendidikannya masih D3 jadi belum ada S1 apoteker terus kemudian dan untuk di laboratorium sendiri masih menggunakan tenaga kesehatan yang lain bukan tenaga lab”

Berdasarkan jawaban dari bapak JS diatas perlu kita ketahui bahwa Puskesmas Malingping masih kekurangan tenaga kerja. Terutama dibagian bidang Farmasi dan Laboratorium seperti kutipan penelitian berikut.

"Kalau itu belum semuanya, tetapi ada yang udah ada yang belum. Seperti contoh, misalnya analis tenaga laboratorium kan harusnya analis tetapi kami belum punya tenaga analis, jadi digantikan dengan bidan dan perawat yang terlatih sebagai analis. Misalnya pemeriksaan pengambilan HB pokoknya pemeriksaan laboratorium sederhana apalagi sekarang ini semenjak masa pandemi kan kasus covid banyak sedangkan analisnya terbatas. Jadi otomatis kita perawat dan bidan juga harus bisa melaksanakan pemeriksaan pengambilan sample gitu. Jadi kalau ditanya sesuai dengan profesinya atau tidak? Ada yang iya ada yang tidak”. 
Berdasarkan jawaban tersebut bahwa di Puskesmas Malingping penempatan pegawai masih belum sesuai karena masih ada tenaga kerja kesehatan yang mengisi dibagian yang bukan dibidangnya.

\section{Pengarahan}

Sebelum pelaksanaan atau kegiatan dilaksanakan ada pengarahan yang diberikan, sesuai dengan program yang akan diberikan dan yang akan dilaksanakan. Seperti kutipan hasil wawancara berikut.

"Pengarahan pasti ada setiap harinya para pegawai mengikuti apel pagi nah disetiap apel pagi itu direview pekerjaan apa dan program apa yang dilaksanakan, setelah itu diberi arahan oleh Kepala TU atau Kepala Puskesmas lalu setiap berangkat untuk menjalani program pun selalu ada bimbingan terlebih dahulu"

Berdasarkan jawaban tersebut dapat diketahui bahwa pengarahan dilakukan setiap apel pagi sebelum melaksanakan kegiatan kerja. Penarahan pelaksanaan kegiatan itu disampaikan bentuk kegiatannya, tujuan-tujuan kegiatannya dan data seperti apa yang dibutuhkan pada saat pelaksanaan kegiatan.

\section{Pengendalian}

Kedisiplinan pegawai sangat penting didalam suatu instansi kesehatan agar dalam pelaksanaan kegiatan berjalan sesuai dengan aturan pemberian tugas dan tanggug jawab harus disertai dengan pengendalian seperti kedisplinan petugas. Seperti hasil wawancara berikut:

"kita disini ada selain Kepala Puskesmas dan Kasubag TU di ruangan itu ada masing-masing kepala ruangannya CI-nya jadi itu mereka yang memberikan laporan-laporan tentang kedisiplinan, jadi setiap seminggu sekali kita memantau dan biasanya rekapitulasinya satu bulan sekali dan kita biacarakan di meeting. Kita bahas di evaluasi meeting, jadi setiap ruangan itu ada kepala ruangannya untuk kedisiplinan itu kita dilihat dari situ dan kalau misalkan pegawai yang tidak disiplin kita berikan teguran dulu, kita coba secara lisan kalau misalnya bandel tidak disiplin kita akan tegur secara tulisan. Kalau untuk saat ini Alhamdulillah belum ada yang sampai dilaporkan ke Dinas oleh kami cukup di internal saja".

Berdasarkan jawaban tersebut dapat diketahui bahwa untuk kedisiplinan kerja di pantau oleh masing-masing kepala ruangan dan setiap sebulan sekali diadakan rekapitulasi laporan masing-masing kedisiplinan pegawai. 
Prosiding The 1st National Conference on Applied Business, Education, \& Technology (NCABET)"

Unversitas Bina Bangsa 2021

DOI Article : 10.46306/ncabet.v1i1.4

Jadi melihat dari hasil wawancara bahwa: Puskesmas Malingping masih kekurangan tenaga ahli dibagian-bagian tertentu seperti sebelumnya dibagian UKP Farmasi dan Analisis Laboratorium yang dikelola tenaga perawat yang seharusnya dikelola tenaga ahli. Jadi untuk penempatan kerjanya masih ada yang tidak sesuai dalam bidang keahliannya berdasarkan pendidikannya. Jadi untuk mengisi kekosongan maka tenaga yang ada dulu yang diberikan tanggung jawab untuk mengelolanya sampai ada tenaga ahli yang diturunkan oleh DinKes yang memang sesuai dibidang yang dibutuhkan Puskesmas Malingping.

\section{PEMBAHASAN}

\section{Perencanaan Sumber Daya Manusia}

Sumber daya manusia kesehatan merupakan asset yang sangat vital, karena itu keberadaannya dalam organiasi tidak bisa digantikan oleh sumber daya lainnya. Betapapun modern teknologi yang digunakan atau seberapa banyak dana yang disipakan, namun tanpa dukungan sumber daya manusia yang memiliki kemampuan professional, semuanya menjadi tidak bermakna (Yuniarsih dan Suwanto)

Ketersediaan sumber daya manusia kesehatan sangat mempengaruhi keberhasilan pembangunan kesehatan. Pengadaan sumber daya manusia kesehatan untuk menetapkan jumlah dan jenis tenaga yang sesuai dengan kebutuhan. Apabila kebutuhan sumber daya manusia tidak direncanakan dengan baik maka akan terjadi kekurangan tenaga yang mempengaruhi pelayanan serta kenyamanan pasien dan mengakibatkan beban kerja meningkat

Perencanaan tenaga kesehatan di Puskesmas harus sesuai dengan tingkat kebutuhan Puskesmas dalam membantu terwujudnya tujuan. Perencanaan yang baik dimulai dengan menetapkan program kepegawaian. Jumlah dan macam profesi tenaga kesehatan di tiap Puskesmas tentu berbeda. Puskesmas di perkotaan akan berbeda sumber daya manusianya dengan Puskesmas di pedesaan. Perencanaan SDM Puseksmas akan disesuaikan dengan tingkat kebutuhan Puskesmas itu sendiri.

Dalam penyusunan kebutuhan sumber daya manusia kesehatan, pengadaannya melalui usulan dari pihak puskesmas dikoordinasikan dengan dinas kesehatan. Menurut hasil wawancara, yang berperan dalam hal pengadaan sumber daya manusia kesehatan ialah dinas kesehatan.

Dalam hal ini kepala puskesmas, kepegawaian dan kepala tata usaha melakukan perencanaan kebutuhan tenaga kesehatan dengan melaporkan kekurangannya ke dinas kesehatan, 
dengan melihat kekosongan tenaga pada puskesmas. Jadi sementara menunggu distribusi tenaga dari dinas kesehatan, kepala puskesmas, kepegawaian dan kepala tata usaha mengarahkan tenaga kesehatan lain untuk mengisi kekosongan yang ada di puskesmas untuk sementara

Hal ini didukung dengan informasi yang didapat dari hasil observasi langsung yaitu di struktur organisasi Puskesmas Malingping ada beberapa pegawai yang penempatannya tidak sesuai dengan latar belakang pendidikan pegawai.

Berdasarkan hasil wawancara yang didapat dari kepala Puskesmas Malingping mengatakan bahwa jenis pegawai yang diterima di Puskesmas Malingping ada yang sesuai dengan kebutuhan dan ada yang juga tidak sesuai dengan kebutuhan. Hasil wawancara dengan KASUBAG TU yaitu Puskesmas saat ini sudah memberikan usulan kepada Dinas Kesehatan untuk menambahkan tenaga kerja yang sesuai dengan yang dibutuhkan oleh Puskesmas Malingping saat ini.

\section{Pengorganisasiaan Sumber Daya Manusia}

Pengorganisasian merupakan suatu proses untuk merancang struktur formal, mengelompokan dan mengatur serta membagi tugas-tugas atau pekerjaan diantara para anggota organisasi agar tujuan organisasi dapat dicapai dengan efisien. Proses pengorganisasian dapat ditunjukkan dengan berbagai prosedur yang sudah ditentukan. Maka dari itu Puskesmas Malingping sudah memiliki prosedur sesuai dengan SOP yang ditetapkan oleh Dinas Kesehatan. Selain itu, setiap program yang dijalankan sudah ditetapkan penanggung jawabnya yang artinya telah sesuai dengan prosedur yang ada di Puskesmas Malingping. Sebagai contoh SOP layanan klinis yang menjamin kesinambungan layanan menurut Keputusan Kepala Puskesmas Malingping Rawat Inap No. 440.080/SK/PKM-MLP/IV/2018 Tentang Layanan Klinis dengan tujuan untuk memberikan layanan klinis yang menjamin kesinambungan layanan masyarakat. Oleh karena itu, program yang akan dijalankan di Puskesmas Malingping tidak akan berjalan tanpa adanya SOP yang sudah ditetapkan. Oleh karena itu, dapat disimpulkan bahwa Puskesmas Malingping memiliki SOP disetiap prosedur yang akan dijalankan.

Sama hal-nya dengan struktur organisasi di Puskesmas Malingping yang sudah ada peraturannya dari Bupati untuk penetapan Kepala Puskesmas, Kepala TU, Bendahara dan yang lainnya dalam bentuk BLUD. Namun beberapa penempatan pegawainya masih belum sesuai dengan latar belakang pendidikan masing-masing dikarenakan kurangnya tenaga kerja yang dibutuhkan. Hal ini didukung dengan adanya tabel struktur organisasi dalam bidang Penanggung 
Prosiding The 1st National Conference on Applied Business, Education, \& Technology (NCABET)"

Unversitas Bina Bangsa 2021

DOI Article : 10.46306/ncabet.v1i1.4

jawab UKP Farmasi dan Lab yang seharusnya dipegang oleh tenaga lab namun di Puskesmas

Malingping menggunakan tenaga kesehatan lain atau seorang perawat. Untuk itu, peneliti memberikan solusi agar Puskesmas Malingping merekrut pegawai baru yang dibutuhkan sesuai dengan keahliannya masing-masing. Berdasarkan uraian diatas tersebut dapat disimpulkan bahwa struktur organisasi di Puskesmas Malingping masih belum sesuai dengan keahlian dalam bidangnya masing-masing.

Pembagian tugas di setiap devisi di Puskesmas Malingping menggunakan sistem musyawarah yang dilakukan oleh setiap anggota devisinya yang akan diajukan kepada Kepala TU dan Kepala Puskesmas jika sudah mendapatkan kesepakatan bersama anggota tersebut. Yang tentu saja harus sesuai dengan keahlian dan kemampuannya. Jika ada anggota yang menolak tugas yang diberikan maka anggota tersebut akan diberikan tugas lain yang sesuai dengan keinginannya. Hal ini tentu saja tidak efektif, seharusnya pembagian tugas di setiap devisi ditentukan langsung oleh Kepala Puskesmas atau Kepala TU untuk menghindari hal-hal yang tidak diinginkan.

Berdasarkan hal tersebut pembagian tugas di setiap devisi tidak sesuai dengan teori yang ada, hal ini didukung dengan hasil wawancara dari setiap narasumber yang mengatakan hal demikian. Oleh karena itu, dapat disimpulkan bahwa Puskesmas Malingping masih belum sesuai dalam memberikan pembagian tugas di setiap devisi.

Untuk penempatan tenaga kerja, Puskesmas Malingping sudah sesuai dengan keahlian, keterampilan dan latar belakang pendidikan. Kecuali untuk beberapa bidang/devisi/program yang puskesmas belum mempunyai tenaga khusus seperti tenaga analis laboratorium, dan tenaga administrasi khususnya keuangan dan teknologi informasi. Untuk itu, Puskesmas Malingping memberikan pelatihan kepada tenaga kerja yang terpilih sebelum menempati posisi tersebut. Solusi yang diberikan oleh peneliti adalah merekrut pegawai baru yang sesuai dengan bidangnya yang dibutuhkan di Puskesmas Malingping.

Hal ini tentu saja sesuai dengan Peraturan Menteri Kesehatan Republik Indonesia Nomor 42 Tahun 2017 yang menyatakan bahwa untuk peningkatan efisiensi dan efektivitas pelaksanaan tugas dan fungsi organisasi instansi pemerintahan maka perlu dilakukan penempatan Aparatur Sipil Negara yang sesuai dengan keahlian dan keterampilan. Berdasarkan hal tersebut dapat disimpulkan bahwa indikasi yang mengarah pada penempatan kerja yang tidak sesuai dengan latar belakang pendidikannya. Artinya dalam penempatan pegawai ada beberapa persyaratan yang menyangkut masalah latar belakang pendidikannya diabaikan. 
Di samping tugas pokok dan fungsi dalam pelaksanaan pelayanan di puskesmas, sebagian besar tenaga kesehatan mempunyai satu atau lebih tugas tambahan. Keadaan ini disebabkan tenaga kesehatan di Puskesmas Malingping terdapat keterbatasan keterampilan berdasarkan latar belakang pendidikan, sebagai akibatnya ada tenaga yang melakukan pekerjaan tidak sesuai dengan keterampilan/keahliannya. Akibatnya, tenaga kesehatan di Puskesmas Malingping sering kali harus melakukan tugas tambahan selain tugas pokoknya yang dipantau langsung oleh Dinas Kesehatan.

Berdasarkan gambaran ini, sangat penting bahwa Puskesmas mempunyai uraian tugas (job description) pada setiap jabatan yang diemban tenaga kesehatan. Uraian tugas ini akan menyebabkan tenaga kesehatan memahami perannya dalam pelaksanaan pelayanan di puskesmas sesuai dengan visi dan misi puskesmas. Sehingga dapat disimpulkan bahwa Puskesmas Malingping masih belum tepat menempatkan pegawai yang sesuai dengan job description-nya.

\section{Pengarahan Sumber Daya Manusia}

Pelatihan merupakan proses membantu pegawai dalam memperoleh atau mempelajari sikap, kemampuan, keahlian, pengetahuan dan prilaku yang spesifik yang dilakukan perusahaan/instansi untuk mencapai tujuan dengan lebih efektif dan efisien. Sehubungan dengan itu, dari hasil wawancara kelima narasumber, Puskesmas Malingping masih belum memiliki program pelatihan secara resmi, Puskesmas Malingping hanya mengirimkan tenaga kerjanya ke Dinas Kesehatan untuk dilatih dan dikembangkan lagi kemampuan kerjanya, baik dari tingkat pusat, provinsi maupun kabupaten, dan pendidikan pelatihan yang sesuai dengan jenjang jabatan fungsional tiap kompetensi sumber daya manusia.

Maka dari itu, seharusnya Puskesmas Malingping sudah memiliki program pelatihan resmi untuk sistem kerja yang lebih efektif. Solusi yang diberikan peneliti yaitu mengajukan program pelatihan secara resmi di Puskesmas itu sendiri kepada Dinas Kesehatan agar terus meningkatkan kompetensi supaya dapat menjadi tenaga professional sesuai dengan bidang masing-masing. Tenaga kesehatan seperti bidan, dokter, perawat dan tenaga kesehatan penunjang lainnya dapat memberikan pelayanan secara langsung kepada masyarakat. Untuk peningkatan kompetensi tenaga kesehatan tersebut bisa didapatkan melalui pendidikan dan pelatihan yang terus-menerus, berkaitan dengan keahlian yang dimilikinya. 
Berdasarkan hal tersebut dapat disimpulkan bahwa pelatihan program di Puskesmas Malingping hanya bisa mengikuti program pelatihan secara resmi melalui pemanggilan khusus oleh Dinas Kesehatan.

Pengarahan yang diberikan sebelum pelaksanaan kegiatan di Puskesmas Malingping pengarahan secara periodik dilakukan mealui briefing pada apel pagi, pertemuan lokarya puskesmas tiap bulan maupun setiap ada kegiatan yang bersifat insidensial. Dalam pengarahan petugas yang diarahkan oleh Kepala Puskesmas atau Kepala TU yang melakukan bimbingan/arahan terlebih dahulu sebleum menjalankan program yang akan dilaksanakan. Hal ini dapat dilihat dari jadwal piket dan rencana kerja di Puskesmas Malingping yang direncanakan melalui evaluasi terlebih dahulu agar program yang dijalankan bisa terarah dengan baik. Berdasarkan hal tersebut dapat disimpulkan bahwa pengarahan program pelaksanaan kegiatan di Puskesmas sudah sesuai dengan SOP yang berlaku di Puskesmas Malingping.

\section{Pengendalian Sumber Daya manusia}

Kedisiplinan pegawai sangat penting didalam suatu instansi kesehatan agar dalam pelaksanaan kegiatan berjalan sesuai dengan aturan pemberian tugas atau tanggung jawab harus disertai dengan pengendalian seperti kedisiplinan petugas. Penerapan absensi pegawai di Puskesmas Malingping melalui manual ataupun fingerprint sangat mudah digunakan sebab pegawai hanya perlu menandatangani atau meletakan jarinya pada penerapan absensi melalui fingerprint maka secara otomatis data pegawai tersebut akan tersimpan dalam database kepegawaian. Akan tetapi dalam penerapan absensi manual maupun fingerprint dalam meningkatkan disiplin kerja masih ditemui beberapa pelanggaran yaitu masih ada beberapa pegawai yang terlambat datang ke kantor, pulang sebelum waktunya dan tidak masuk tanpa keterangan.

Untuk hal itu perlu diadakannya evaluasi seperti pengawasan, pengontrolan serta pemahaman tentang konsekuensi terhadap pegawai oleh Kepala Puskesmas selaku pemimpin agar pegawai lebih berhati-hati dalam bertindak. Adapun penngendallian disiplin lainnya yaitu penilaian kerja setiap akhir tahun yang dibuat dalam bentuk Sasaran Kinerja Pegawai (SKP) yang berisi target dan hasil kinerja serta perilaku kerja orientasi pelayanan, integritas, komitmen, disiplin, kerjasama. Berdasarkan hal tersebut dapat disimpulkan bahwa penerapan kedisiplinan di Puskesmas Malingping menggunakan system absensi manual dan fingerprint dan untuk penilaian kerja akhir tahunnya dibuat laporan dalam bentuk SKP. 
Ditinjau dari segi keilmuan disiplin pada hakekatnya adalah latihan batin dan watak dengan maksud agar segala perbuatan selalu menaati tata tertib yang ditetapkan pada suatu organisasi kemasyarakatan maupun Negara, dan ukutan disiplin yang baik yaitu bagaimana kita dapat mengukur disiplin secara umum yaitu apabila para pegawai datang ke tempat kerja dengan teratur dan tepat waktu, kualitas pekerjaan. Dan peraturan yang diberikan dengan Puskesmas Malingping.

Mengingat betapa pentingnya disiplin kerja pegawai dilingkungan Puskesmas Malingping, maka dalam pelaksanaannya, mematuhi, menaati semua peraturan-peraturan kerja telah ditetapkan dengan cara setiap pegawai haruslah benar-benar melaksanakan disiplin dengan memperhatikan ketentuan-ketentuan yang diberikan kepada pegawai agar dilakukan dengan baik. Disiplin pegawai pada Puskesmas Malingping telah menunjukkan betapa besar rasa tanggungjawab terhadap disiplin dalam melaksanakan tugas merupakan salah satu peraturan kerja yang harus ditaati dan dipatuhi. Dalam melaksanakan tugas atau pekerjaannya. Seorang pegawai harus benar-benar konsekuen terhadap apa yang dikerjakan

Dengan adanya rasa tanggungjawab yang tinggi terhadap tugas yang diberikan, maka pekerjaan yang dilakukan oleh pegawai akan dapat berjalan dengan lancer tanpa adanya rasa keterpaksaan dalam melaksanakan pekerjaan tersebut, dalam melaksanakan peraturan-peraturan kerja merupakan kunci dari keberhasilan. Dengan adanya disiplin pegawai yang tinggi, maka setiap pekerja dapat melihat manfaat dan disipin tersebut. Oleh karena itu, disiplin harus ditanamkan pada diri pribadi masing-masing.

\section{KESIMPULAN DAN SARAN}

Kesimpulan dari penelitian ini menunjukkan bahwa sistem manajemen sumber daya manusia di Puskesmas Malingping meliputi empat aspek yaitu perencanaan, pengorganisasiaan, pengarahan dan pengendalian.

Evaluasi sistem manajemen sumber daya manusia menunjukkan bahwa sistem manajemen sumber daya manusia pada penempatan kerja di UPT Puskesmas Malingping masih belum maksimal dikarenakan berlebihnya tenaga kesehatan Bdan dan Perawat dan kurangnya kebutuhan tenaga kerja yang mengakibatkan penempatan kerja yang tidak sesuai dengan disiplin ilmu.

Berdasarkan hasil yang diperoleh dalam penelitian ini, penulis ingin mengemukakan beberapa saran, yaitu:

1. Bagi pegawai Puskesmas Malingping 
Diharapkan mampu memberikan kontribusi kepada organisasi atau lembaga tertentu dalam memahami fungsi dari manajemen SDM atau proses pengelolaan manusia agar menjadi produktif, efektif dan efisien.

2. Bagi Peneliti selanjutnya

Bagi peneliti selanjutnya bisa menambahkan variabel lain yang dapat dijadikan indikator dalam penelitian lanjutan. Hal ini karena masih adanya variabel-variabel yang belum ditemukan penulis yang masih memiliki hubungan yang berkaitan dengan penempatan kerja

3. Bagi Instansi/Lembaga

Perlu mengatur kembali sumber daya manusia kesehatan yang sesuai dengan tugas dan fungsi. Serta segera dilakukan pelatihan untuk manajemen puskesmas secara berkala dan berkesinambungan agar sistem manajemen sumber daya manusia kesehatan di puskesmas lebih baik.

\section{UCAPAN TERIMAKASIH}

1. Kepada kedua orang tua yang senantiasa memberikan do'a dan dukungannya sehingga penulis dapat menyelesaikan penelitian ini.

2. Dr. H.Furtasan Ali Yusuf, S.E., S.Kom., M.M, selaku Rektor Universitas Bina Bangsa yang telah berperan aktif dalam meningkatkan mutu dan kualitas Universitas Bina Bangsa menjadi perguruan tinggi yang lebih baik.

3. Kepada seluruh Dosen, staf administrasi, rekan-rekan mahasiswa dan sahabat yang telah memberikan bantuan sehingga penulis dapat menyelesaikan penelitian ini.

\section{DAFTAR PUSTAKA}

Antri Mariza, Syafrijuana, Analisis Penempatan Pegawai Pada Puskesmas Sungai Tutung Kecamatan Air Hangat Timur Kabupaten Kerinci, Jurnal Administrasi Nusantara Mahasiswa STIA Nusantara Sakti Sungai Penuh Vol.3 No.5-31 Mei 2021

Arifudin dkk, Evaluasi Sistem Manajemen Sumber Daya Manusia pada Penempatan Kerja Petugas di UPT Puskesmas Lembasada, Universitas Muhammadiyah Palu, Jurnal Riset Manajemen Sumber Daya Manusia Vol.7, No.1, Juli 2017

Cupian, dkk, Analisis Pelaksanaan Rekrutmen, Seleksi dan Penempatan Berdasarkan Perspektif Islamic Human Capital, Jurnal Ilmiah Manajemen, Vol.1 No.1, April 2020 
Dedi Arfiyanto, Isnanis Yuli, Pengendalian Sumber Daya Manusia Pada KARYAWAN Universias Wiraja Bagian Struktural dalam Pencapaian Prestasi kerja, Jurnal Performance Bisnis dan Akuntasi, Vol VI, No. 2, September 2016

Grace A. Salamate, dkk, Analisis Perencanaan Sumber Daya Manusia Kesehatan di Dinas Kesehatan Kabupaten Minahasa Tenggara, Jurnal Dinas Kesehatan Kabupaten Minahasa Tenggara Fakultas Kesehatan Masyarakat Universitas Sam Ratulangi Manado

Hendrayadi, Antri Mariza Qadarsih dan Syafrijuana, Analisis Penempatan Pegawai pada Puskesmas Sungai Tutung Kecamatan Air Handat Timur Kabupaten Kerinci, Jurnal STIA Nusantara Sakti Sungai Penuh

Kholil dkk, Konsep Dasar Sistem, Jurnal Riset Mekanisme Sistem (Jakarta, 2019)

Ni Putu Riski Martini, Pegaruh Penempatan Sumber Daya Manusia Pada Kinerja Karyawan di Pemerintah Kabupaten Badung, Jurnal Riset Akuntasi Vol.9, No.1 Juli 2017 